\title{
Ichnocarpus frutescens Ameliorates Experimentally Induced Convulsion in Rats
}

\author{
Narendra Kumar Singh, ${ }^{1}$ Damiki Laloo, ${ }^{2}$ Debapriya Garabadu, ${ }^{2}$ \\ Tryambak Deo Singh, ${ }^{1}$ and Virendra Pratap Singh ${ }^{1}$ \\ ${ }^{1}$ Department of Medicinal Chemistry, Faculty of Ayurveda, Institute of Medical Sciences, Banaras Hindu University, \\ Varanasi 221 005, India \\ ${ }^{2}$ Department of Pharmaceutics, Indian Institute of Technology, Banaras Hindu University, Varanasi 221 005, India
}

Correspondence should be addressed to Narendra Kumar Singh; narendra_pharma1982@rediffmail.com

Received 4 June 2014; Accepted 10 September 2014; Published 29 October 2014

Academic Editor: Giuseppe Maurizio Campo

Copyright (C) 2014 Narendra Kumar Singh et al. This is an open access article distributed under the Creative Commons Attribution License, which permits unrestricted use, distribution, and reproduction in any medium, provided the original work is properly cited.

\begin{abstract}
The present study was carried out to evaluate the anticonvulsant activity and probable mechanism of action of the methanol root extract from I. frutescens (MEIF) using different experimental animal models. Anticonvulsant activity of the single dose of MEIF (100, 200, and $400 \mathrm{mg} / \mathrm{kg}$, p.o.) was evaluated in maximal electroshock- (MES-), pentylenetetrazole- (PTZ-), and isoniazid(INH-) induced convulsions models in rats. The levels of $\gamma$-amino butyric acid (GABA), glutamate, GABA-transaminase (GABA-T) activity and oxidative stress markers were measured in pretreated rat's brain homogenate to corroborate the mechanism of observed anticonvulsant activity. MEIF (200-400 mg/kg, p.o.) protected the animals in all the behavioral models used. Pretreatment of MEIF $(200-400 \mathrm{mg} / \mathrm{kg}$, p.o.) and diazepam $(1.0 \mathrm{mg} / \mathrm{kg}$, i.p.) to the animals in INH-induced convulsion model showed $100 \%$ and $80 \%$ protection, respectively, as well as significant restoration of GABA and glutamate level in the rat's brain. MEIF and vigabatrin $(50 \mathrm{mg} / \mathrm{kg}$, i.p.) reduced the PTZ-induced increase in the activity of GABA-T (46\%) in the brain. Further, MEIF reversed the PTZinduced increase in lipid peroxidase (LPO) and decrease in reduced glutathione (GSH), catalase (CAT), and superoxide dismutase (SOD) activities. The findings of this study validate the anticonvulsant activity of $I$. frutescens.
\end{abstract}

\section{Introduction}

Epilepsy is the result of abnormal, hypersynchronous neuronal activity (a lot of irregular neuronal activity) [1], affecting approximately 50 million of the people worldwide with an approximate estimation of at least 7 million in India [2,3]. The term epilepsy is used for the brain disorder, characterized by occurrence of spontaneous seizures (convulsion, sensory disturbances, or loss of consciousness resulting from the abnormal electrical discharges in the brain), due to the imbalance of complex neurotransmitter systems [4]. Clinically, epilepsy can be classified into two broad categories, namely, partial seizures (discharge remains localized) and generalized seizures (involves the whole brain). Either form is classified as simple (if consciousness is not lost) or complex (if consciousness is lost). Two important subcategories of generalized seizures are tonic clonic seizures (grand mal) and absence seizures (petit mal) [5]. Pharmacotherapy of epilepsy includes phenytoin, carbamazepine, valproate, ethosuximide, phenobarbital, benzodiazepines, vigabatrin, and gabapentin; however their use is restricted based on certain severe adverse effects such as hypersensitivity, sedation, megaloblastic anaemia, and teratogenic effect [5]. Thus, it is a prerequisite to search for an alternative and effective source as an antiepileptic drug with a good safety profile and lesser side effects. Recently, herbal medicines gained critical attention as a good source of alternate medicine for the treatment of various disorders due to lesser side effects [6]. It has been reported that several medicinal plants such as Abelmoschus angulosus Wall. ex Wight \& Arn. (Malvaceae), Allium sativum L. (Amaryllidaceae), Cinchona officinalis L. (Rubiaceae), Plumbago zeylanica L. (Plumbaginaceae), and 
Egletes viscosa (L.) Less. (Asteraceae) are used since time immemorial for the treatment of epilepsy in the Indian system of traditional medicine [7].

Ichnocarpus frutescens (L.) R. Br. (Apocynaceae) is a woody climber, distributed in India, ascending to an altitude of up to $4000 \mathrm{ft}$ above sea level [8]. Traditionally, most of the ethnic communities in India used this plant for the treatment of diabetes, skin diseases, epilepsy, chronic nervous diseases, debility, impotence, abdominal distention, and gall bladder stone [9-12]. I. frutescens root is one of the important ingredients of the Ayurvedic formulations "Ashwagandharishta" and "Swalpachaitasa Ghrita," which are indicated for the treatment of epilepsy and other ailments [13]. The important phytoconstituents reported from this plant are $\alpha$-L-rhamnopyranosyl-( $1 \rightarrow 4)$ - $\beta$-D-glucopyranosyl- $(1 \rightarrow$ 3)- $\alpha$-amyrin [14], $\alpha$-amyrin, lupeol, $\beta$-sitosterol, friedelin, epi-friedelinol [15], apigenin, luteolin [16], kaempferol, kaempferol-3-galactoside, ursolic acid acetate [17], quercetin, and quercetin-3-O- $\beta$-D-glucopyranoside [18]. Pharmacologically, various activities have been reported from this plant which include antiurolithiatic, hepatoprotective, antiinflammatory, antipyretic, analgesic, antidiabetic, anticancer, antihyperlipidemic, and antioxidant activities [12]. Traditionally, the root of this plant is used in the treatment for epilepsy; however no scientific information has been reported so far to validate the anticonvulsant activity in experimental animals. Hence, the present investigation was designed to scientifically validate the antiepileptic activity of the methanol extract from the root of I. frutescens (MEIF) using MES-, PTZ-, and INHinduced convulsion models in rats.

Amino acid transmitters particularly play an important role in the pathogenesis of epileptic conditions $[19,20]$. It is well accepted that changes in amino acids concentration in the brain following convulsions include decrease in inhibitory amino acids level such as GABA, taurine, and alanine and an increase in the concentration of the excitatory amino acids level such as aspartate and glutamate [21]. Thus, the present study was designed to explore the effect of MEIF on the level of GABA and glutamate in the INH-induced model of epilepsy. Further, the effect of MEIF was investigated on the GABA-T activity and oxidative stress in the PTZinduced convulsion model.

\section{Materials and Methods}

2.1. Chemicals and Reagents. Pentylenetetrazole, isoniazid, gamma aminobutyric acid, glutamate, diazepam (D-907), phenytoin (PHR1139), and vigabatrin were purchased from Sigma Ltd., USA. ELISA kit (MBS939900; MyBioSource, Inc., San Diego, CA, USA) was used for the estimation of GABA-T activity.

2.2. Plant Material. Plant material was collected in the month of December (2011) from the medicinal garden of Rajiv Gandhi South Campus, Banaras Hindu University, Barkachha, Mirzapur, UP, India. The identification of the plant material was done by Dr. Subir Bandyopadyay at the Botanical Survey of India, Howrah, West Bengal, India (plant identification letter: CNH/104/2012/Tech. II/950). For future reference a voucher specimen (number PRL-02) of the plant material has been deposited in the Department of Medicinal Chemistry, Faculty of Ayurveda, Institute of Medical Sciences, Banaras Hindu University, Varanasi.

2.3. Preparation of Plant Extract. Roots of I. frutescens were separated from the aerial parts and shade-dried until a constant weight was obtained. The roots were then pulverized into coarse powder and sieved by $20 \#$ sieve. The coarse powdered drug (475 g) was extracted with methanol (2.0 l) by cold maceration process for 10 days. After 10 days the content was filtered and the filtrate obtained was concentrated under reduced pressure in rotary evaporator (Perfit India, Pvt. Ltd., India) below $60^{\circ} \mathrm{C}$. Methanol extract of $I$. frutescens (MEIF) $(5.26 \% \mathrm{w} / \mathrm{w})$ obtained was kept in desiccator for several days to completely remove the traces of solvent.

2.4. Animals. Inbred Charles Foster rats (120-150 g) of either sex were obtained from the Central Animal House of Banaras Hindu University, Varanasi. The experimental study was performed after receiving necessary approval from the Institutional Animal Ethical Committee (IAEC), Institute of Medical Sciences, Banaras Hindu University, Varanasi (Dean/1314/CAEC/193). All the animals were housed and maintained under standard laboratory conditions in polypropylene cages at constant room temperature $\left(22.0 \pm 3.0^{\circ} \mathrm{C}\right)$, relative humidity $(50 \pm 10 \%)$, and $12: 12 \mathrm{~h}$ dark and light cycle. The animals were allowed to acclimatize to the environment of the laboratory for 7 days before the commencement of experiments. Animals were fed with commercial rat feed (Amrut, Pvt. Ltd., Pune, India) and water ad libitum. Each animal was used for one seizure experiment only. Fasting of the animals (with free access to water ad libitum) for $18 \mathrm{~h}$ prior to the experiment was done in all the tested anticonvulsant models.

2.5. Acute Toxicity Studies. The acute oral toxicity study of MEIF was performed according to the Organization for Economic Co-Operation and Development (OECD)-425 guidelines. Single dose of MEIF $2000 \mathrm{mg} / \mathrm{kg}$, p.o., was administered in $24 \mathrm{~h}$ fasted rats $(n=5)$ and rats were observed at $0,30,60,120,180$, and $240 \mathrm{~min}$ and then once a day for the next 14 days for any signs or symptoms of toxicity or abnormalities. The number of rats that survived at the end of the study period was recorded [22].

\subsection{Evaluation of Anticonvulsant Activity of MEIF in Different Animal Models of Convulsion}

2.6.1. Maximal Electroshock- (MES-) Induced Convulsion. The maximal electroshock seizure (MES) was tested in animals through transauricular electrodes attached bilaterally to the animal ear. Electroconvulsive shock producing an alternating current stimulus ( $150 \mathrm{~mA}, 50 \mathrm{~Hz}, 0.2 \mathrm{~s}$ duration) was delivered through ear-clip electrodes to induce hind limb tonic extension (HLTE) in rats. The electrodes were moistened with a drop of electrolyte solution prior to delivery of the electroshock [23]. Animals were divided into five 
groups of six animals in each group $(n=6)$. Group I (negative control) served as untreated group and received only carboxymethyl cellulose $(0.5 \% \mathrm{CMC}$, p.o.). Group II (standard treated group) received single dose of phenytoin (25 mg/kg, i.p.), whereas Groups III, IV, and V (MEIF treated groups) received the single dose of the MEIF 100, 200, and $400 \mathrm{mg} / \mathrm{kg}$, p.o., respectively. All the animals received electric shock stimulation $30 \mathrm{~min}$ after the treatment with standard drug and graded dose of MEIF. After electrical stimulation, the occurrence and duration of HLTE and incidence of mortality were noted. The criterion for the evaluation of anticonvulsant activity is the ability to prevent HLTE or reduction in the duration of HLTE [24].

2.6.2. Isoniazid- (INH-) Induced Convulsion. In INH-induced convulsion model, animals were randomly divided into six groups comprising six animals in each group $(n=6)$. Group I (normal control) received only vehicle (0.5\% CMC, p.o.). Group II (negative control) was administered with INH ( $250 \mathrm{mg} / \mathrm{kg}$, i.p.) only. Group III (standard treated group) received standard drug diazepam $(1.0 \mathrm{mg} / \mathrm{kg}$, i.p.). Groups IV, V, and VI (MEIF treated groups) were administered with MEIF 100, 200, and $400 \mathrm{mg} / \mathrm{kg}$, p.o. Convulsion was induced to all the animals (except Group I) by single dose administration of INH (250 mg/kg, i.p.) after $30 \mathrm{~min}$ of the treatment with the MEIF and the standard drug. All the animals were carefully monitored for $30 \mathrm{~min}$ for the occurrence of convulsions. The latency of convulsions was recorded and the percentage protection was calculated [25]. Thereafter, all the animals were anaesthetized and decapitated and whole brain was collected and stored at $-80^{\circ} \mathrm{C}$ for the estimation of GABA and glutamate levels. All the animals were disposed by cremation.

(1) Chromatographic Estimation of GABA and Glutamate in Whole Brain. GABA and glutamate levels were estimated in rat brain using high performance liquid chromatography (HPLC, Waters, USA). Briefly, brain tissues were homogenized in $0.1 \mathrm{M}$ perchloric acid containing $4 \mathrm{mM}$ sodium metabisulphite solution ( $30 \mu \mathrm{L}$ per $10 \mathrm{mg}$ of tissue) [26]. The resulting homogenate was centrifuged at $10000 \mathrm{rpm}$ at $4^{\circ} \mathrm{C}$ for $15 \mathrm{~min}$ and the residual pellet was separated from the supernatant. The supernatant obtained was filtered through a syringe (Millex-HN filter, $0.45 \mu \mathrm{m}$ ). Pellet and filtered supernatant were stored separately in Eppendorf tubes at $-80^{\circ} \mathrm{C}$ until the analysis. Concentrations of GABA and glutamate were measured using precolumn derivatization with $o$-phthalaldehyde (OPA) and fluorescence was detected [27]. Derivatization was performed by mixing $20 \mu \mathrm{L}$ filtered supernatant with $6 \mu \mathrm{L} \mathrm{OPA}$ and injecting this mixture into the solvent stream of the HPLC system, 2 min later. Separation of OPA-GABA and OPA-glutamate was carried out on a reversed phase $3.9 \times 150 \mathrm{~mm}$ column (Nova-Pack, $4 \mu \mathrm{m}$, $\mathrm{C} 18$, Waters) at $35^{\circ} \mathrm{C}$ using a binary gradient system of mobile phases A and B (mobile phase A: $38.74 \mathrm{mM}$ sodium acetate dissolved in 90\% milli-Q water and 10\% methanol, pH 5.75; mobile phase B: buffer containing 20\% solution A and $80 \%$ methanol, $\mathrm{pH} 6.75$ ) at a flow rate of $0.5 \mathrm{~mL} / \mathrm{min}$. Fluorometric detection was performed with a fluorescence detector (Waters, 474) at excitation and emission wavelengths of 360 and $450 \mathrm{~nm}$, respectively. This procedure allowed the quantification of GABA and glutamate levels by linear regression using external standards (Sigma, USA). Protein content was determined using the residual pellet according to a modified version of Bradford's method [28]. GABA and glutamate content in the brain tissue were expressed as $\mu \mathrm{g} / \mathrm{mg}$ protein.

2.6.3. Pentylenetetrazole- (PTZ-) Induced Convulsion. In PTZ-induced convulsion model, the animals were randomly divided into six groups with six animals in each group $(n=6)$. Group I (normal control) received vehicle (0.5\% CMC, p.o.) only. Group II (negative control) received PTZ $(90 \mathrm{mg} / \mathrm{kg}$, i.p.), whereas Group III (standard treated group) received vigabatrin (50 mg/kg, i.p.). Groups IV, V, and VI (MEIF treated groups) received MEIF 100, 200, and $400 \mathrm{mg} / \mathrm{kg}$, p.o., respectively. Convulsion was induced in all the animals (except Group I) by single dose administration of PTZ (90 mg/kg, i.p.) after $30 \mathrm{~min}$ of the treatment with the extract or standard drug. Animals which showed no convulsions within $30 \mathrm{~min}$ were considered as protected and the percentage protection in each group was calculated. In unprotected animals, the latency of the first convulsion was recorded $[29,30]$. All the animals were carefully monitored for $30 \mathrm{~min}$ for any behavioral change related to convulsion. Finally, after the observation, all the animals were anaesthetized and decapitated and the whole brain was collected for the estimation of GABA-T activity and oxidative stress markers. All the animals were disposed by cremation.

(1) Estimation of GABA-T Activity and Oxidant Stress Markers. $500 \mathrm{mg}$ of rat brain tissue was taken and rinsed with phosphate buffer solution (PBS, $\mathrm{pH}$ 7.2-7.4). Brain tissue was homogenized in $5.0 \mathrm{~mL}$ of PBS and stored overnight at $-20^{\circ} \mathrm{C}$. The homogenates were centrifuged for $5 \mathrm{~min}$ at $5000 \times g$ maintaining the temperature between 2 and $8^{\circ} \mathrm{C}$. The supernatant obtained was assayed for the estimation of both GABA-T activity and oxidant stress markers.

(1.1) Estimation of GABA-T Activity. The supernatant of brain homogenate was assayed for GABA-T activity spectrophotometrically at $450 \mathrm{~nm}$ using commercially available ELISA kit (MBS939900; MyBioSource, Inc., San Diego, CA, USA). GABA-T was expressed as $\mathrm{pg} / \mathrm{mg}$ protein.

(1.2) Estimation of LPO Activity. Lipid peroxidation was measured and expressed in terms of malondialdehyde (MDA) as per the method of Liu et al. [31]. $1.0 \mathrm{~mL}$ of supernatant was added with $1.5 \mathrm{~mL}(20 \%, \mathrm{pH} 3.5)$ acetic acid reagent, $1.5 \mathrm{~mL}$ thiobarbituric acid $(0.8 \%)$, and $0.2 \mathrm{~mL}$ sodium dodecyl sulphate $(8.1 \%)$. The reaction mixture was heated at $100^{\circ} \mathrm{C}$ for $60 \mathrm{~min}$ and then cooled under tap water. The mixture was then mixed with $1.0 \mathrm{~mL}$ of distilled water and $5.0 \mathrm{~mL}$ of $n$-butanol and pyridine mixture $(15: 1)$ and vortexed vigorously. The organic layer was separated after centrifugation at $4000 \mathrm{rpm}$ for $10 \mathrm{~min}$. Absorbance of organic layer was 
measured by using spectrophotometer at $532 \mathrm{~nm}$ and the concentration was expressed as nmol MDA/g tissue.

(1.3) Estimation of GSH Activity. Reduced glutathione activity was measured as per the method of Sedlak and Lindsay [32]. Trichloroacetic acid (50\%) was added with equal quantity of brain homogenate and centrifuged at $3000 \mathrm{rpm}$ for $15 \mathrm{~min}$. $1.5 \mathrm{~mL}$ of the supernatant was mixed with $4.0 \mathrm{~mL}$ of $0.4 \mathrm{M}$ Tris buffer and $0.1 \mathrm{~mL}$ of $5,5^{\prime}$-dithio-bis-(2-nitrobenzoic acid) (DTNB). The mixture was vigorously vortexed and the absorbance was recorded within $5 \mathrm{~min}$ after the addition of DTNB at $412 \mathrm{~nm}$ against reagent blank. The results were expressed as $\mu \mathrm{g} \mathrm{GSH} / g$ of tissue.

(1.4) Estimation of SOD Activity. SOD activity was determined as per the method of Kakkar et al. [33]. Brain homogenate $(0.4 \mathrm{~mL})$ was added with $1.2 \mathrm{~mL}, 0.052 \mathrm{M}$ sodium pyrophosphate buffer ( $\mathrm{pH} 8.3$ ), $0.1 \mathrm{~mL}$ of $186 \mu \mathrm{M}$ phenazine methosulphate, $0.3 \mathrm{~mL}$ of $300 \mu \mathrm{M}$ nitroblue tetrazolium (NBT), and $0.8 \mathrm{~mL}$ of distilled water. This mixture was added with $2.0 \mathrm{~mL}$ of $780 \mu \mathrm{M}$ NADH solution and incubated at $30^{\circ} \mathrm{C}$ for $60 \mathrm{sec}$. After incubation, the reaction was terminated by the addition of $1.0 \mathrm{~mL}$ of glacial acetic acid. The reaction mixture was then shaken vigorously with $4.0 \mathrm{~mL}$ of $n$-butanol and later centrifuged at $3000 \mathrm{rpm}$ for $5 \mathrm{~min}$. The butanol layer was separated and the color intensity was measured at $560 \mathrm{~nm}$ against $n$-butanol. A system devoid of enzyme served as control. SOD activity in the homogenate was expressed as unit of SOD activity/g of tissue.

(1.5) Estimation of CAT Activity. Catalase activity was determined according to the method described by Aebi [34]. Brain homogenate $(20 \mu \mathrm{L})$ was added to a cuvette containing $2.0 \mathrm{~mL}$ of phosphate buffer ( $\mathrm{pH} 7.0$ ) and $1.0 \mathrm{~mL}$ of $30 \mathrm{mM} \mathrm{H}_{2} \mathrm{O}_{2}$. Catalase activity was measured by using spectrophotometer at $240 \mathrm{~nm}$ for $1 \mathrm{~min}$ and expressed as unit of CAT activity/g of tissue.

2.7. Statistical Analysis. All the results were expressed as mean $\pm \operatorname{SEM}(n=6)$. The analysis of variance was done by using one-way ANOVA followed by Tukey's posttest for multiple groups comparison. The difference was considered to be significant when $P<0.05$. GraphPad Prism (version 5) software was used for all statistical analyses.

\section{Results}

3.1. Acute Toxicity Studies. MEIF at the dose of $2000 \mathrm{mg} / \mathrm{kg}$, p.o., did not exhibit any behavioral changes or symptoms of toxicity. Hence the drug was found to be safe up to the tested dose of $2000 \mathrm{mg} / \mathrm{kg}$, p.o.

3.2. Effect of MEIF on MES-Induced Convulsion. Oral administration of MEIF (100, 200, and $400 \mathrm{mg} / \mathrm{kg}$, p.o.) and phenytoin $(25 \mathrm{mg} / \mathrm{kg}$, i.p.) exhibited significant reduction in the duration of tonic convulsion when compared to

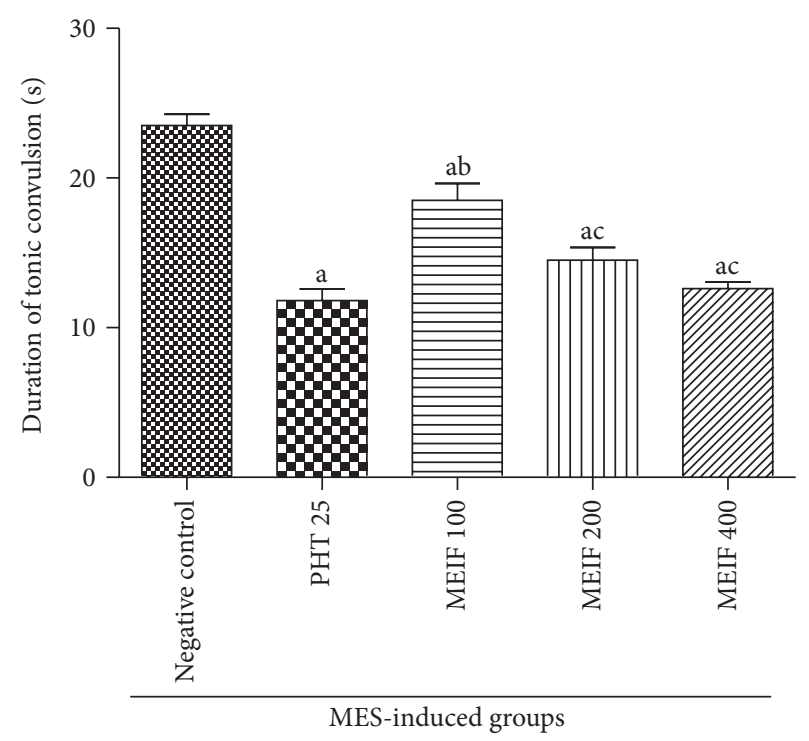

FIGURE 1: Effect of MEIF (100-400 mg/kg, p.o.) on MES-induced convulsion model in rats. Values are expressed as mean \pm SEM $(n=6)$. Statistical comparison was analyzed by one-way ANOVA followed by Tukey's multiple comparison test. ${ }^{\mathrm{a}} \mathrm{P}<0.05$, statistically significant as compared to negative control; ${ }^{\mathrm{b}} P<0.05$, statistically significant as compared to phenytoin (PHT $25 \mathrm{mg} / \mathrm{kg}$, i.p.); ${ }^{\mathrm{C}} P<$ 0.05 , statistically significant as compared to MEIF ( $100 \mathrm{mg} / \mathrm{kg}$, p.o.).

negative control group. However, when compared to phenytoin $(25 \mathrm{mg} / \mathrm{kg}$, i.p.) treated group, MEIF $(200-400 \mathrm{mg} / \mathrm{kg}$, p.o.) exhibited no significant difference in reduction of the duration of HLTE, thus revealing that the potency of the extract is comparable to that of phenytoin (Figure 1).

3.3. Effect of MEIF on INH-Induced Convulsion. INH $(250 \mathrm{mg} / \mathrm{kg}$, i.p.) exhibited HLTE in all the six animals of negative control group. Diazepam $(1 \mathrm{mg} / \mathrm{kg}$, i.p.) produced $100 \%$ protection against the convulsion induced by INH. However, MEIF (200-400 mg/kg, p.o.) exhibited significant protection (up to $80 \%$ ) and increased the latency of tonic convulsion as compared to negative control group (Table 1).

3.3.1. Effect of MEIF on the Level of GABA and Glutamate. Rats administered with INH $(250 \mathrm{mg} / \mathrm{kg}$, i.p.) showed significant reduction in the level of GABA by $69 \%$ and elevation in the level of glutamate by $59 \%$ in the brain homogenate when compared to normal control rats. Diazepam $(1 \mathrm{mg} / \mathrm{kg}$, i.p.) and MEIF (200-400 mg/kg, p.o.) produced significant recovery in the level of GABA, whereas the level of glutamate was observed to decrease significantly. MEIF $(100 \mathrm{mg} / \mathrm{kg}$, p.o.) did not produce any significant activity in recovering the level of GABA and reduction in the level of glutamate (Table 2).

3.4. Effect of MEIF on PTZ-Induced Convulsion. Animal groups treated with MEIF (200-400 mg/kg, p.o.) and vigabatrin $(50 \mathrm{mg} / \mathrm{kg}$, i.p.) showed significant increase in the latency of tonic convulsions induced by PTZ (90 mg/kg, p.o.) 
TABLE 1: Effect of MEIF graded dose on INH-induced convulsion in rats.

\begin{tabular}{lccccc}
\hline & $\begin{array}{c}\text { Treatments dose } \\
\text { INH } \\
(\mathrm{mg} / \mathrm{kg}, \text { i.p. })\end{array}$ & $\begin{array}{c}\text { Diazepam } \\
(\mathrm{mg} / \mathrm{kg}, \mathrm{i} . \mathrm{p})\end{array}$ & $\begin{array}{c}\text { MEIF } \\
(\mathrm{mg} / \mathrm{kg}, \mathrm{p} . \mathrm{o})\end{array}$ & $\begin{array}{c}\text { Number } \\
\text { convulsed/number used }\end{array}$ & $\begin{array}{c}\text { \% Animals protected } \\
\text { Latency of tonic } \\
\text { convulsion (min) } \\
(\mathrm{mean} \pm \text { SEM) }\end{array}$ \\
\hline 250 & - & - & $6 / 6$ & 0 & $13.20 \pm 1.00$ \\
250 & - & 100 & $5 / 6$ & 16.67 & $17.04 \pm 0.59$ \\
250 & - & 200 & $3 / 6$ & 50 & $20.55 \pm 0.80^{\mathrm{a}}$ \\
250 & - & 400 & $1 / 6$ & 83.33 & $27.75 \pm 2.55^{\mathrm{abc}}$ \\
250 & 1.0 & - & $0 / 6$ & 100 & $\infty^{\mathrm{a}}$ \\
\hline
\end{tabular}

Values are expressed as mean \pm SEM $(n=6)$. Statistical comparison was analyzed by one-way ANOVA followed by Tukey's multiple comparison test. ${ }^{\text {a } P<}$ 0.05 , statistically significant as compared to negative control; ${ }^{\mathrm{b}} P<0.05$, statistically significant as compared to $\mathrm{MIEF}\left(100 \mathrm{mg} / \mathrm{kg}\right.$, p.o.); ${ }^{\mathrm{c}} P<0.05$, statistically significant as compared to MEIF (200 mg/kg, p.o.).

TABLE 2: Effect of MEIF graded dose on GABA and glutamate level in brain homogenate.

\begin{tabular}{|c|c|c|c|c|}
\hline \multirow[b]{2}{*}{ INH (mg/kg, i.p.) } & \multicolumn{2}{|c|}{ Treatments dose } & \multirow[b]{2}{*}{ GABA ( $\mu \mathrm{g} / \mathrm{mg}$ protein $)$} & \multirow[b]{2}{*}{ Glutamate ( $\mu \mathrm{g} / \mathrm{mg}$ protein) } \\
\hline & $\begin{array}{c}\text { Diazepam } \\
\text { (mg/kg, i.p.) }\end{array}$ & $\begin{array}{c}\text { MEIF } \\
\text { (mg/kg, p.o.) }\end{array}$ & & \\
\hline- & - & - & $33.13 \pm 1.22$ & $52.38 \pm 1.57$ \\
\hline 250 & - & - & $10.21 \pm 0.92^{\mathrm{a}}$ & $126.27 \pm 15.25^{\mathrm{a}}$ \\
\hline 250 & 1.0 & - & $25.17 \pm 3.96^{\mathrm{b}}$ & $66.63 \pm 1.20^{\mathrm{b}}$ \\
\hline 250 & - & 100 & $15.63 \pm 3.50^{\mathrm{a}}$ & $105.15 \pm 10.49^{\mathrm{ac}}$ \\
\hline 250 & - & 200 & $24.01 \pm 3.71^{\mathrm{b}}$ & $82.58 \pm 4.65^{\mathrm{b}}$ \\
\hline 250 & - & 400 & $25.60 \pm 1.16^{\mathrm{b}}$ & $74.67 \pm 3.23^{\mathrm{b}}$ \\
\hline
\end{tabular}

Values are expressed as mean $\pm \operatorname{SEM}(n=6)$. Statistical comparison was analyzed by one-way ANOVA followed by Tukey's multiple comparison test. ${ }^{\mathrm{a}} P<$ 0.05 , statistically significant as compared to normal control; ${ }^{\mathrm{b}} P<0.05$, statistically significant as compared to negative control (INH); ${ }^{\mathrm{c}} P<0.05$, statistically significant as compared to diazepam $1.0 \mathrm{mg} / \mathrm{kg}$, i.p.

as compared to negative control group. The percentage protection was observed to be as high as up to $66 \%$ and $100 \%$ when the rats were, respectively, treated with MEIF and standard drug vigabatrin (Table 3 ).

3.4.1. Effect of MEIF on GABA-T Activity. Rats administered with PTZ $(90 \mathrm{mg} / \mathrm{kg}$, i.p.) showed significant increase in the level of GABA-T enzymatic activity by $46 \%$ as compared to normal control group. Treatment of the animals with standard drug vigabatrin $(50 \mathrm{mg} / \mathrm{kg}$, i.p.) and MEIF (200$400 \mathrm{mg} / \mathrm{kg}$, p.o.) produced a significant reduction in the level of GABA-T enzyme when compared to negative control group. However, the lower dose of MEIF ( $100 \mathrm{mg} / \mathrm{kg}$, p.o.) showed no significant effect in the reduction of enzyme activity (Figure 2).

3.4.2. Effect of MEIF on the Level of Oxidative Stress Markers. The results in Table 4 depict that rats administered with PTZ $(90 \mathrm{mg} / \mathrm{kg}$, i.p.) showed significant increase in the level of LPO, while significant reduction in the level of SOD, GSH, and CAT was observed as compared to normal control group. Diazepam (1 mg/kg, i.p.) and MEIF ( $400 \mathrm{mg} / \mathrm{kg}$, p.o.) significantly produced an excellent reduction in the level of LPO and increased the level of SOD, GSH, and CAT significantly. MEIF (200 mg/kg, p.o.) also showed a similar effect but was found to be ineffective in restoring the levels of

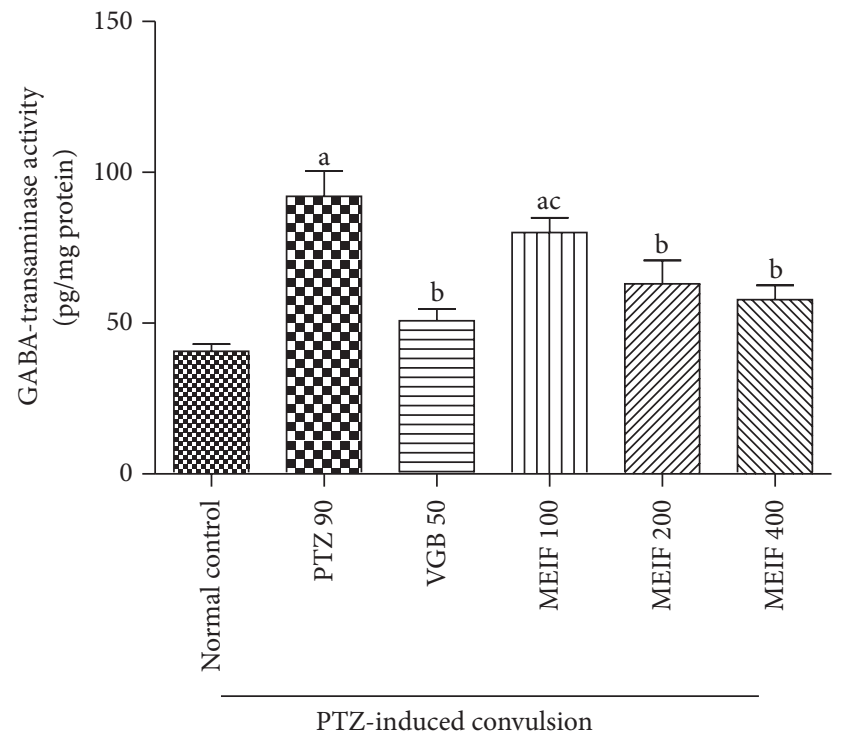

FigURE 2: Effect of MEIF (100-400 mg/kg, p.o.) on GABA-T activity in PTZ-induced convulsion model in rats. Values are expressed as mean \pm SEM $(n=6)$. Statistical comparison was analyzed by oneway ANOVA followed by Tukey's multiple comparison test. ${ }^{\mathrm{a}} \mathrm{P}<$ 0.05 , statistically significant as compared to normal control; ${ }^{b} P<$ 0.05 , statistically significant as compared to negative control (PTZ $90 \mathrm{mg} / \mathrm{kg}$, i.p.); ${ }^{\mathrm{c}} P<0.05$, statistically significant as compared to vigabatrin (VGB $50 \mathrm{mg} / \mathrm{kg}$, i.p.). 
TABLE 3: Effect of MEIF graded dose on pentylenetetrazole- (PTZ-) induced convulsion in rats.

\begin{tabular}{|c|c|c|c|c|c|}
\hline $\begin{array}{l}\text { PTZ } \\
\text { (mg/kg, i.p.) }\end{array}$ & $\begin{array}{l}\text { Treatments dose } \\
\text { Vigabatrin } \\
\text { (mg/kg, i.p.) }\end{array}$ & $\begin{array}{c}\text { MEIF } \\
\text { (mg/kg, p.o.) }\end{array}$ & $\begin{array}{l}\text { Number } \\
\text { convulsed/number used }\end{array}$ & $\%$ Animals protected & $\begin{array}{l}\text { Latency of tonic } \\
\text { convulsion }(\mathrm{min}) \\
(\text { mean } \pm \text { SEM })\end{array}$ \\
\hline 90 & - & - & $6 / 6$ & 0 & $10.7 \pm 0.34$ \\
\hline 90 & - & 100 & $5 / 6$ & 16.67 & $12.2 \pm 0.41$ \\
\hline 90 & - & 200 & $4 / 6$ & 33.33 & $13.0 \pm 0.55^{\mathrm{a}}$ \\
\hline 90 & - & 400 & $0 / 6$ & 66.67 & $16.6 \pm 0.65^{\mathrm{abc}}$ \\
\hline 90 & 50 & - & $0 / 6$ & 100 & $\infty^{\mathrm{a}}$ \\
\hline
\end{tabular}

Values are expressed as mean \pm SEM $(n=6)$. Statistical comparison was analyzed by one-way ANOVA followed by Tukey's multiple comparison test. ${ }^{\text {a } P<}$ 0.05 , statistically significant as compared to negative control; ${ }^{\mathrm{b}} P<0.05$, statistically significant as compared to $\mathrm{MIEF}\left(100 \mathrm{mg} / \mathrm{kg}\right.$, p.o.); ${ }^{\mathrm{c}} P<0.05$, statistically significant as compared to MEIF (200 mg/kg, p.o.).

TABLE 4: Effect of MEIF graded dose on pentylenetetrazole- (PTZ-) induced convulsion in rats.

\begin{tabular}{|c|c|c|c|c|c|c|}
\hline \multicolumn{3}{|c|}{ Treatments dose } & \multirow{2}{*}{$\begin{array}{l}\text { LPO } \\
\text { (nmole MDA/g brain } \\
\text { tissue) }\end{array}$} & \multirow{2}{*}{$\begin{array}{l}\text { SOD } \\
\text { (unit/g brain tissue) }\end{array}$} & \multirow{2}{*}{$\begin{array}{l}\text { CAT } \\
\text { (unit/g brain tissue) }\end{array}$} & \multirow{2}{*}{$\begin{array}{l}\text { GSH } \\
(\mu \mathrm{g} / \mathrm{g} \text { brain tissue })\end{array}$} \\
\hline $\begin{array}{l}\text { PTZ } \\
\text { (mg/kg, i.p.) }\end{array}$ & $\begin{array}{l}\text { Vigabatrin } \\
\text { (mg/kg, i.p.) }\end{array}$ & $\begin{array}{c}\text { MEIF } \\
(\mathrm{mg} / \mathrm{kg}, \text { p.o. })\end{array}$ & & & & \\
\hline- & - & - & $20.12 \pm 0.82$ & $30.53 \pm 0.48$ & $25.02 \pm 0.65$ & $256.4 \pm 19.24$ \\
\hline 90 & - & - & $52.87 \pm 0.96^{\mathrm{a}}$ & $15.13 \pm 3.03^{\mathrm{a}}$ & $11.47 \pm 1.12^{\mathrm{a}}$ & $121.02 \pm 14.20^{\mathrm{a}}$ \\
\hline 90 & 50 & - & $23.17 \pm 1.83^{b}$ & $26.70 \pm 1.92^{\mathrm{b}}$ & $23.14 \pm 1.30^{\mathrm{b}}$ & $242.0 \pm 11.98^{\mathrm{b}}$ \\
\hline 90 & - & 100 & $43.29 \pm 2.72^{\mathrm{abc}}$ & $18.27 \pm 1.71^{\mathrm{a}}$ & $15.35 \pm 0.83^{\mathrm{ac}}$ & $192.57 \pm 12.75^{\mathrm{b}}$ \\
\hline 90 & - & 200 & $38.62 \pm 2.81^{\mathrm{abc}}$ & $21.56 \pm 2.35^{\mathrm{a}}$ & $19.85 \pm 0.76^{\mathrm{abd}}$ & $218.90 \pm 17.80^{\mathrm{b}}$ \\
\hline 90 & - & 400 & $28.28 \pm 2.2^{\text {bde }}$ & $25.75 \pm 1.60^{\mathrm{b}}$ & $21.73 \pm 1.02^{\mathrm{bd}}$ & $235.86 \pm 13.31^{\mathrm{b}}$ \\
\hline
\end{tabular}

Values are expressed as mean \pm SEM $(n=6)$. Statistical comparison was analyzed by one-way ANOVA followed by Tukey's multiple comparison test. ${ }^{a} P<$ 0.05 , statistically significant as compared to normal control; ${ }^{\mathrm{b}} P<0.05$, statistically significant as compared to negative control $(\mathrm{PTZ} 90) ;{ }^{\mathrm{c}} P<0.05$, statistically significant as compared to standard vigabatrin $\left(50 \mathrm{mg} / \mathrm{kg}\right.$, i.p.); ${ }^{\mathrm{d}} P<0.05$, statistically significant as compared to MEIF $\left(100 \mathrm{mg} / \mathrm{kg}\right.$, p.o.); ${ }^{\mathrm{e}} P<0.05$, statistically significant as compared to MEIF ( $200 \mathrm{mg} / \mathrm{kg}$, p.o.).

SOD. However, MEIF (100 mg/kg, p.o.) showed a significant recovery in the levels of LPO and GSH, but no effect was observed on SOD and CAT levels (Table 4).

\section{Discussion}

The objective of the present study was to investigate the protective effect of MEIF (100, 200, and $400 \mathrm{mg} / \mathrm{kg}$, p.o.) against physical and chemical induced convulsion in experimental rat models. MEIF (200 and $400 \mathrm{mg} / \mathrm{kg}$, p.o.) dosedependently reduced the convulsions in MES treated rats. Pretreatment of MEIF (200 and $400 \mathrm{mg} / \mathrm{kg}$, p.o.) reversed INH-induced decrease and increase in the level of GABA and glutamate in the rat brain, respectively. MEIF (200 and $400 \mathrm{mg} / \mathrm{kg}$, p.o.) attenuated the PTZ-induced increase in the activity of GABA-T in the rat brain. Further, MEIF (200 and $400 \mathrm{mg} / \mathrm{kg}$, p.o.) reversed the PTZ-induced increase in the level of LPO and decrease in GSH, CAT, and SOD levels.

Root of $I$. frutescens is an important ingredient of many Ayurvedic formulations, commonly used for the treatment of epilepsy along with other diseases, but has not been investigated scientifically. In MES-induced convulsion model, neither phenytoin nor MEIF (200 and $400 \mathrm{mg} / \mathrm{kg}$, p.o.) protected the animal completely, but a significant reduction in the duration of tonic convulsion was observed. Lower dose of MEIF (100 mg/kg, p.o.) showed no significant reduction in the duration of convulsion in MES exposed animals. MES induces seizure particularly due to the spread of stimulus throughout the body and anticonvulsant drugs that block the effect of MES act by blocking the seizure spread [35]. Thus, the present study indicates that MEIF (200 and $400 \mathrm{mg} / \mathrm{kg}$, p.o.) has significant ability to slow down the spread of seizure.

Epilepsy is a condition of spontaneous recurrent seizures having a close relation with the $\mathrm{GABA}_{\mathrm{A}}$ receptor [36]. Seizure is the result of the imbalance between excitatory and inhibitory neurotransmitters in the brain [37]. GABA and glutamate are, respectively, the most important inhibitory and excitatory neurotransmitters located in the mammalian brain [5]. Glutamic acid decarboxylase (GAD) is a key enzyme in the biogenesis of GABA from glutamic acid in the neurons, thereby maintaining a balance between GABA and glutamate. It is well known that INH-induced seizure is attributed mainly to the inhibition of the enzyme GAD in the neurons that ultimately lead to the depletion and elevation in the level of GABA and glutamate in the brain, respectively [38]. Drugs that decrease the activity of glutamatergic system and/or increase the activity of GABAergic system are beneficial in the therapeutic strategy of epilepsy. Therefore, the levels of GABA and glutamate were estimated in INH-induced convulsion model of epilepsy to elucidate the effect of MEIF $(100,200$, and $400 \mathrm{mg} / \mathrm{kg}$, p.o.) on these two neurotransmitters' activity. In the present study, INH 
(250 mg/kg, i.p.) significantly decreased and increased the level of GABA and glutamate, respectively, in the rat brain. Diazepam (1 mg/kg, i.p.) and MEIF (200 and $400 \mathrm{mg} / \mathrm{kg}$, p.o.) significantly reversed the INH-induced changes in the levels of both GABA and glutamate in rat brain. This indicates that MEIF (200 and $400 \mathrm{mg} / \mathrm{kg}$, p.o.) may probably be able to retain the balance between GABA and glutamate levels during seizure.

As MEIF (200 and $400 \mathrm{mg} / \mathrm{kg}$, p.o.) reversed the INHinduced decrease in the GABAergic activity, we further investigated the effect of MEIF $(100,200$, and $400 \mathrm{mg} / \mathrm{kg}$, p.o.) in PTZ-induced animal model of convulsion. It is well reported that $\mathrm{PTZ}$ induces convulsion through antagonism at the picrotoxin-sensitive site of $\mathrm{GABA}_{\mathrm{A}}$ receptor complex [39]. As a result, the glutamatergic activity predominates over GABAergic activity which leads to convulsion in the animals. In addition, it has also been reported that PTZ increases the level of GABA-T in the brain [40]. Drugs showing protective effect against the PTZ-induced tonic clonic convulsion are considered in the treatment of myoclonic and absence seizure in humans [41].

In the present study, standard drug vigabatrin $(50 \mathrm{mg} / \mathrm{kg}$, i.p.) showed complete protection against PTZ-induced convulsion while MEIF (200 and $400 \mathrm{mg} / \mathrm{kg}$, p.o.) showed dosedependent effect against PTZ-induced convulsion. GABA$\mathrm{T}$ is the primary catabolic enzyme in the mammalian brain that catalyzes the transfer of amino group from GABA to $\alpha$ ketoglutarate leading to the depletion in the level of GABA [42]. PTZ significantly increased the level of GABA-T activity in the rat brain. Administration of MEIF $(200-400 \mathrm{mg} / \mathrm{kg}$, p.o.) and vigabatrin (50 mg/kg, i.p.) significantly attenuated the enzyme activity indicating potent GABA-T inhibitory effect. It is well studied that free radicals are generated during convulsion and disturb the balance between GABA and glutamate activity in the brain $[43,44]$. Thus, in addition to GABA-T inhibitory activity, we have attempted to estimate the markers of oxidative damage in the brain of PTZ exposed rats. PTZ (90 mg/kg, i.p.) significantly increased the activity of LPO enzyme and reduced the activity of antioxidant enzymes such as SOD, CAT, and GSH in the rat brain. Both standard drug and MEIF (200 and $400 \mathrm{mg} / \mathrm{kg}$, p.o.) decreased the PTZ-induced increase in the activity of LPO. On the contrary, both increased the PTZ-induced decrease in the activities of SOD, GSH, and CAT in the brain. This indicates that MEIF (200 and $400 \mathrm{mg} / \mathrm{kg}$, p.o.) has profound antioxidant activity in convulsive rats.

Literature survey reveals that MEIF is a rich source of triterpenoids, phenolics, and steroids [12]. Recently, $\alpha$ amyrin and ursolic acid have been isolated from MEIF and standardized by HPTLC [45]. I. frutescens is also reported to contain quercetin along with other phenolics [12]. It has been reported that ursolic acid (triterpenoid) has significant GABA-T inhibitory activity in in vitro study [46] and protects against the PTZ-induced convulsion in rats [47]. Quercetin, a phenolic component, has been reported to reduce the seizure and duration of convulsion in amygdala electrical kindling model in rats [48]. Moreover, $\alpha$-amyrin (triterpenoid) retains a balance between excitatory and inhibitory neurotransmitters in convulsion [49]. Phenolics are also well known for their antioxidant activity in convulsive animals. Thus, the polyphenols in the MEIF may be responsible for the anticonvulsant activity through modulating GABAergic system and oxidative stress in the brain.

\section{Conclusion}

Hence, from the present study, it can be concluded that MEIF (200-400 mg/kg, p.o.) showed anticonvulsant activity through modulating GABAergic system and oxidative stress in the rat's brain which can be predicted due to the presence of different category of phytoconstituents (phenolics, terpenoids, and steroids). Therefore, roots of $I$. frutescens could be a potential source in the management of convulsion.

\section{Conflict of Interests}

The authors declare no conflict of interests regarding the present study.

\section{Acknowledgment}

The authors are thankful to the Botanical Survey of India, Howrah, West Bengal, India, for the identification of plant material.

\section{References}

[1] G. Bertini, P. Bramanti, G. Constantin et al., "New players in the neurovascular unit: insights from experimental and clinical epilepsy," Neurochemistry International, vol. 63, no. 7, pp. 652659, 2013.

[2] S. P. Dhanabal, N. Paramakrishnan, S. Manimaran, and B. Suresh, "Anticonvulsant potential of essential oil of Artemisia abrotanum," Current Trends in Biotechnology and Pharmacy, vol. 1, no. 1, pp. 112-116, 2007.

[3] A. S. Galanopoulou, P. S. Buckmaster, K. J. Staley et al., "Identification of new epilepsy treatments: issues in preclinical methodology," Epilepsia, vol. 53, no. 3, pp. 571-582, 2012.

[4] A. Mandegary, M. Arab-Nozari, H. Ramiar, and F. Sharififar, "Anticonvulsant activity of the essential oil and methanolic extract of Bunium persicum (Boiss). B. Fedtsch," Journal of Ethnopharmacology, vol. 140, no. 2, pp. 447-451, 2012.

[5] H. P. Rang, M. M. Dale, J. M. Ritter, and P. K. Moore, Pharmacology, Churchill Livingstone, Edinburgh, UK, 2000.

[6] M. Ayyanar and S. Ignacimuthu, "Ethnobotanical survey of medicinal plants commonly used by Kani tribals in Tirunelveli hills of Western Ghats, India," Journal of Ethnopharmacology, vol. 134, no. 3, pp. 851-864, 2011.

[7] L. J. Quintans Jr., J. R. G. S. Almeida, J. T. Lima et al., "Plants with anticonvulsant properties-a review," Brazilian Journal of Pharmacognosy, vol. 18, pp. 798-819, 2008.

[8] Indian Council of Medical Research, Medicinal Plants of India, Indian Council of Medical Research, New Delhi, India, 1987.

[9] V. Singh and R. P. Pandey, "Medicinal plant-lore of the tribal's of eastern Rajasthan, India," Journal of Economic \& Taxonomic Botany, vol. 1, pp. 137-147, 1980.

[10] A. K. Goel and V. Mudgal, "A survey of medicinal plants used by the tribals of Santal Pargana, Bihar," Journal of Economic \& Taxonomic Botany, vol. 12, pp. 329-335, 1988. 
[11] M. K. Rai, "Ehtnomedicinal survey of Patalkot and Tamiya (District Chhindwara): plants used against skin diseases and liver disorders," Journal of Economic \& Taxonomic Botany, vol. 12, pp. 337-339, 1988.

[12] N. K. Singh and V. P. Singh, "Phytochemistry and pharmacology of Ichnocarpus frutescens," Chinese Journal of Natural Medicines, vol. 10, no. 4, pp. 241-246, 2012.

[13] N. N. Sengupta, The Ayurvedic System of Medicine, Volume I, Logos Press, New Delhi, India, 1994.

[14] P. K. Minocha and R. N. Tandon, "A new triterpene glycoside from the stem of Ichnocarpus frutescens," Phytochemistry, vol. 19, no. 9, pp. 2053-2055, 1980.

[15] D. K. M. Lakshmi, E. V. Rao, and D. V. Rao, "Triterpenoid constituents of Ichnocarpus frutescens," Indian Drugs, vol. 22, no. 10, pp. 552-553, 1985.

[16] M. Daniel and S. D. Sabnis, "Chemotaxonomical studies on apocynaceae," Indian Journal of Experimental Biology, vol. 16, no. 4, pp. 512-513, 1978.

[17] M. S. Y. Khan, K. Javed, and M. H. Khan, "Chemical constituents of the leaves of Ichnocarpus frutescens," Journal of Indian Chemical Society, vol. 72, no. 1, pp. 65-66, 1995.

[18] R. P. Singh, "Flavanoids of the flowers of Ichnocarpus farutescens," Journal of Indian Chemical Society, vol. 64, no. 11, pp. 715-716, 1987.

[19] S. G. Brickley, S. G. Cull-Candy, and M. Farrant, "Development of a tonic form of synaptic inhibition in rat cerebellar granule cells resulting from persistent activation of GABA(A) receptors," The Journal of Physiology, vol. 497, no. 3, pp. 753-759, 1996.

[20] J.-M. Fritschy and P. Panzanelli, "Molecular and synaptic organization of $\mathrm{GABA}_{\mathrm{A}}$ receptors in the cerebellum: effects of targeted subunit gene deletions," Cerebellum, vol. 5, no. 4, pp. 275-285, 2006.

[21] M. González-Ramírez, L. I. Razo-Juárez, J. L. SauerRamírez, M. E. González-Trujano, H. Salgado-Ceballos, and S. Orozco-Suarez, "Anticonvulsive effect of vitamin C on pentylenetetrazol-induced seizures in immature rats," Pharmacology Biochemistry and Behavior, vol. 97, no. 2, pp. 267-272, 2010.

[22] OECD/OCDE, OECD Guidelines for the Testing of Chemicals: Guidance no. 425. Acute Oral Toxicity: Up and Down Procedure (UDP), 2008, http://ntp.niehs.nih.gov/iccvam/suppdocs/feddocs/oecd/oecdtg425.pdf.

[23] M. Sayyah, J. Valizadeh, and M. Kamalinejad, "Anticonvulsant activity of the leaf essential oil of Laurus nobilis against pentylenetetrazole- and maximal electroshock-induced seizures," Phytomedicine, vol. 9, no. 3, pp. 212-216, 2002.

[24] M. M. Castel-Branco, G. L. Alves, I. V. Figueiredo, A. C. Falcão, and M. M. Caramona, "The maximal electroshock seizure (MES) model in the preclinical assessment of potential new antiepileptic drugs," Methods and Findings in Experimental and Clinical Pharmacology, vol. 31, no. 2, pp. 101-106, 2009.

[25] R. Bernasconi, M. Klein, P. Martin et al., " $\gamma$-Vinyl GABA: comparison of neurochemical and anticonvulsant effects in mice," Journal of Neural Transmission: General Section, vol. 72, no. 3, pp. 213-233, 1988.

[26] M. A. Peat and J. W. Gibb, "High-performance liquid chromatographic determination of indoleamines, dopamine, and norepinephrine in rat brain with fluorometric detection," Analytical Biochemistry, vol. 128, no. 2, pp. 275-280, 1983.

[27] K. M. Kendrick, E. B. Keverne, C. Chapman, and B. A. Baldwin, "Microdialysis measurement of oxytocin, aspartate, $\gamma$-aminobutyric acid and glutamate release from the olfactory bulb of the sheep during vaginocervical stimulation," Brain Research, vol. 442, no. 1, pp. 171-174, 1988.

[28] M. M. Bradford, "A rapid and sensitive method for the quantitation of microgram quantities of protein utilizing the principle of protein dye binding," Analytical Biochemistry, vol. 72, no. 1-2, pp. $248-254,1976$.

[29] J. A. O. Ojewole, "Anticonvulsant effect of Rhus chirindensis (Baker F.) (Anacardiaceae) stem-bark aqueous extract in mice," Journal of Ethnopharmacology, vol. 117, no. 1, pp. 130-135, 2008.

[30] M. S. Patil, C. R. Patil, S. W. Patil, and R. B. Jadhav, "Anticonvulsant activity of aqueous root extract of Ficus religiosa," Journal of Ethnopharmacology, vol. 133, no. 1, pp. 92-96, 2011.

[31] J. Liu, R. Edamatsu, H. Kabuto, and A. Mori, "Antioxid ant action of Guilingji in the brain of rats with $\mathrm{FeCl}_{3}$-induced epilepsy," Free Radical Biology and Medicine, vol. 9, no. 5, pp. 451-454, 1990.

[32] J. Sedlak and R. H. Lindsay, "Estimation of total, proteinbound, and nonprotein sulfhydryl groups in tissue with Ellman's reagent," Analytical Biochemistry, vol. 25, no. 1, pp. 192-205, 1968.

[33] P. Kakkar, B. Das, and P. N. Viswanathan, "A modified spectrophotometric assay of superoxide dismutase," Indian Journal of Biochemistry and Biophysics, vol. 21, no. 2, pp. 130-132, 1984.

[34] H. E. Aebi, "Catalase," in Methods of Enzymatic Analysis, H. U. Bergmeyer, Ed., pp. 273-286, Chemie, Weinhem, Germany, 1983.

[35] M. A. Rogawski and R. J. Porter, "Antiepileptic drugs: pharmacological mechanisms and clinical efficacy with consideration of promising developmental stage compounds," Pharmacological Reviews, vol. 42, no. 3, pp. 223-286, 1990.

[36] A. L. Sherwin, "Neuroactive amino acids in focally epileptic human brain: a review," Neurochemical Research, vol. 24, no. 11, pp. 1387-1395, 1999.

[37] J. E. Cacazos and R. M. Sanchez, "Mechanisms of seizures and epilepsy," in Epilepsy: Scientific Foundations of Clinical Practice, J. M. Rho, R. Sankar, and J. E. Cavazos, Eds., pp. 5-20, Marcel Dekker, New York, NY, USA, 2004.

[38] M. Vergnes, A. Boehrer, S. Reibel, S. Simler, and C. Marescaux, "Selective susceptibility to inhibitors of GABA synthesis and antagonists of GABA(A) receptor in rats with genetic absence epilepsy," Experimental Neurology, vol. 161, no. 2, pp. 714-723, 2000.

[39] R. Ramanjaneyulu and M. K. Ticku, "Interactions of pentamethylenetetrazole and tetrazole analogues with the picrotoxinin site of the benzodiazepine-GABA receptor-ionophore complex," European Journal of Pharmacology, vol. 98, no. 3-4, pp. 337-345, 1984.

[40] L. A. V. Rasgado, G. C. Reyes, and F. V. Díaz, "Effect of convulsant drugs in GDH activity and oxygen consumption in mouse brain," Journal of Medicine and Medical Sciences, vol. 4, no. 1, pp. 34-42, 2013.

[41] M. Nisar, I. Khan, S. U. Simjee, A. H. Gilani, and H. Perveen, "Anticonvulsant, analgesic and antipyretic activities of Taxus wallichiana Zucc," Journal of Ethnopharmacology, vol. 116, no. 3, pp. 490-494, 2008.

[42] F. M. Sherif and S. Saleem Ahmed, "Basic aspects of GABAtransaminase in neuropsychiatric disorders," Clinical Biochemistry, vol. 28, no. 2, pp. 145-154, 1995.

[43] C. N. Oliver, P. E. Starke-Reed, E. R. Stadtman, G. J. Liu, J. M. Carney, and R. A. Floyd, "Oxidative damage to brain proteins, 
loss of glutamine synthetase activity, and production of free radicals during ischemia/reperfusion-induced injury to gerbil brain," Proceedings of the National Academy of Sciences of the United States of America, vol. 87, no. 13, pp. 5144-5147, 1990.

[44] B. Halliwell and M. C. Gutteridge, "Oxygen is poisonous, an introduction to oxygen toxicity and free radicals," in Free Radicals in Biology and Medicine, B. Halliwell and M. C. Gutteridge, Eds., pp. 1-20, Clarendon Press, Oxford, UK, 2nd edition, 2009.

[45] N. K. Singh and V. P. Singh, "Anticancer activity of the roots of Ichnocarpus frutescens R. Br. and isolated triterpenes," Pakistan Journal of Pharmaceutical Sciences, vol. 27, no. 1, pp. 187-191, 2014.

[46] R. Awad, A. Muhammad, T. Durst, V. L. Trudeau, and J. T. Arnason, "Bioassay-guided fractionation of lemon balm (Melissa officinalis L.) using an in vitro measure of GABA transaminase activity," Phytotherapy Research, vol. 23, no. 8, pp. 1075-1081, 2009.

[47] M. F. Taviano, N. Miceli, M. T. Monforte, O. Tzakou, and E. M. Galati, "Ursolic acid plays a role in Nepeta sibthorpii Bentham CNS depressing effects," Phytotherapy Research, vol. 21, no. 4, pp. 382-385, 2007.

[48] T. Baluchnejadmojarad, M. Roghani, and H. Homayounfar, "Inhibitory effect of high dose of the flavonoid quercetin on amygdala electrical kindling in rats," Basic and Clinical Neuroscience, vol. 1, no. 3, pp. 57-61, 2010.

[49] G. F. Aragão, L. M. V. Carneiro, A. P. F. Junior, P. N. Bandeira, T. L. G. Lemos, and G. S. D. B. Viana, "Evidence for excitatory and inhibitory amino acids participation in the neuropharmacological activity of alpha- and beta-amyrin acetate," The Open Pharmacology Journal, vol. 3, no. 1, pp. 9-16, 2009. 

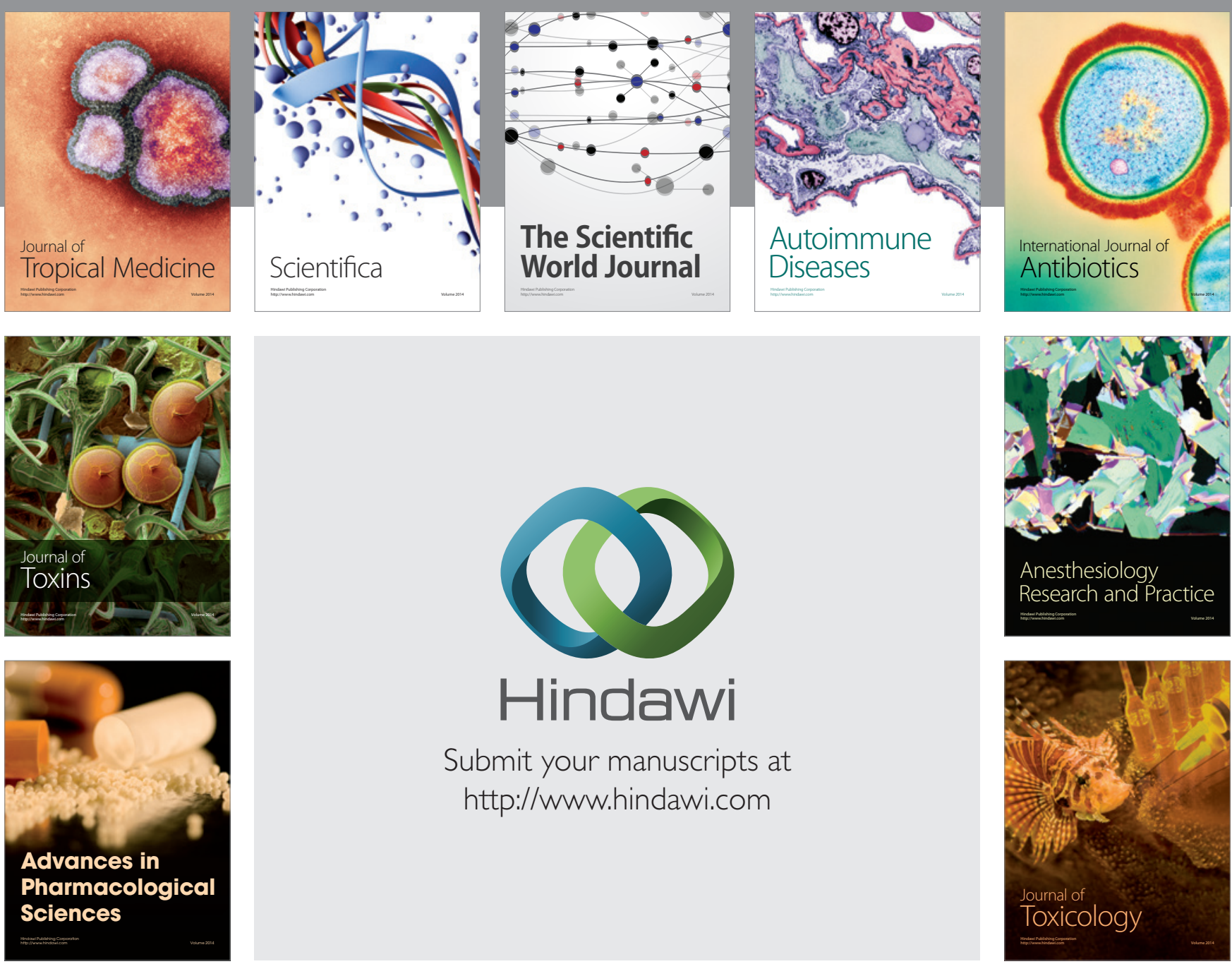

\section{Hindawi}

Submit your manuscripts at

http://www.hindawi.com
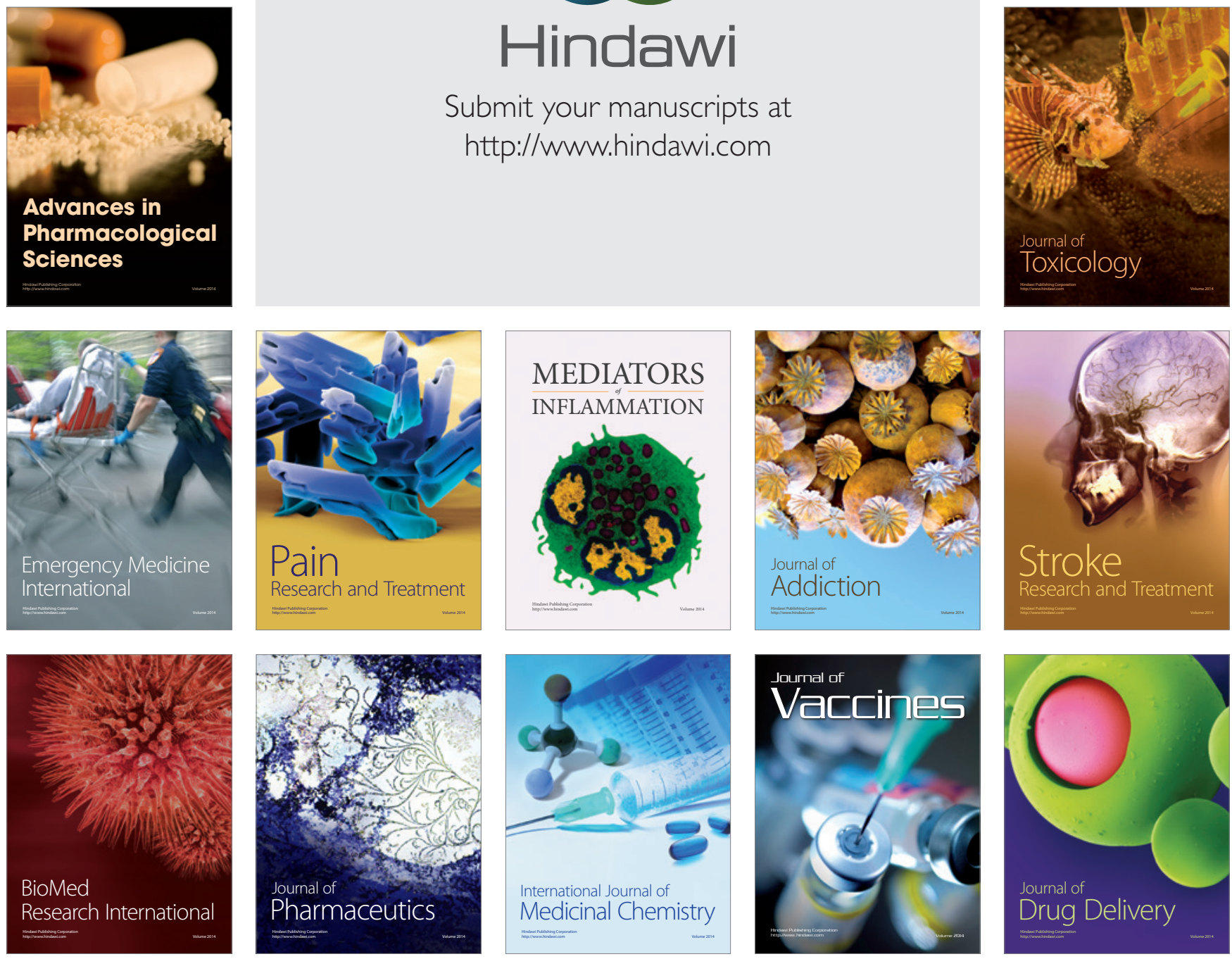